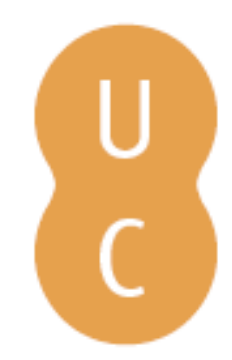

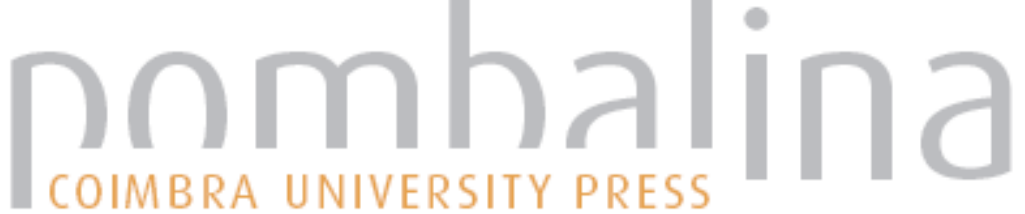

\section{Las aguas del mar en Edipo Rey y Edipo en Colono de Sófocles}

Autor(es): $\quad$ López Rodríguez, Concepción

Publicado por: Imprensa da Universidade de Coimbra

URL

persistente: URI:http://hdl.handle.net/10316.2/45100

DOI: $\quad$ DOl:https://doi.org/10.14195/978-989-26-1568-4_5

Accessed : $\quad$ 26-Apr-2023 14:10:27

A navegação consulta e descarregamento dos títulos inseridos nas Bibliotecas Digitais UC Digitalis, UC Pombalina e UC Impactum, pressupõem a aceitação plena e sem reservas dos Termos e Condições de Uso destas Bibliotecas Digitais, disponíveis em https://digitalis.uc.pt/pt-pt/termos.

Conforme exposto nos referidos Termos e Condições de Uso, o descarregamento de títulos de acesso restrito requer uma licença válida de autorização devendo o utilizador aceder ao(s) documento(s) a partir de um endereço de IP da instituição detentora da supramencionada licença.

Ao utilizador é apenas permitido o descarregamento para uso pessoal, pelo que o emprego do(s) título(s) descarregado(s) para outro fim, designadamente comercial, carece de autorização do respetivo autor ou editor da obra.

Na medida em que todas as obras da UC Digitalis se encontram protegidas pelo Código do Direito de Autor e Direitos Conexos e demais legislação aplicável, toda a cópia, parcial ou total, deste documento, nos casos em que é legalmente admitida, deverá conter ou fazer-se acompanhar por este aviso. 


\section{O melhor é a água}

\section{Da antiguidade clássica aos}

nossos dias

José Luís Brandão \& Paula Barata Dias (coords.) 


\title{
LAS AGUAS DEL MAR EN EDIPO REYY EDIPO EN COLONO DE SÓFOCLES
}

\section{(The Waters of the Sea in Oedipus Rex and Oedipus at Colonus by Sophocles)}

\author{
Concepción López Rodríguez (clopez@ugr.es) \\ Universidad de Granada \\ orcid.org/0000-0002-4266-0512
}

\begin{abstract}
Resumen - Las agitadas aguas del mar aparecen en la tragedia Edipo Rey para crear un escenario de dolor, destrucción y muerte. El mar en Edipo en Colono, junto con los manantiales y la tierra, configuran un "espacio sagrado" intemporal, localizado en el santuario de Posidón en Colono (Atenas), temenos donde descansará Edipo.

Palabras clave - metáfora, lenguaje, tragedia, Sófocles.
\end{abstract}

Авstract - The turbulent seawaters of Oedipus Tyrannus create a scene of illness, destruction and death. Together with natural springs and the earth, the sea is represented as a timeless sacred space in Oedipus Coloneus, located in the Sanctuary of Poseidon at Colonus (Athens), the divine temenos where Oedipus will rest.

KEYwords - metaphor, language, tragedy, Sophocles.

Con el título propuesto quiero ofrecer algunos matices de la presencia del mar, de un mar real y constante en el pensamiento y en la literatura griegos, y de un mar como referente imaginario de gran valor en la ejecución dramática sofoclea, que amplía el conflicto trágico a dimensiones cósmicas, dotándolo a la vez de un conmovedor efecto poético. Se analizan, pues, algunos ejemplos de las tragedias dedicadas a Edipo. Al centrar mi estudio en ellas, se percibe mejor la hábil utilización del mar estrechamente vinculado al desarrollo dramático de un mismo personaje y se constatan las variaciones de tono que Sófocles nos ofrece, desde un gobernante que asume el mando de un Estado hasta la de un anciano ciego, que busca en su querida Colono un lugar donde un tranquilo Posidón lo acoja en el recinto demarcado de las Euménides. Dos momentos, pues, de la vida de Edipo que arrastran consigo un diferente diseño dramático y una diferente dimensión del logos. Constatar cómo se amenguan o cómo se engrandecen las aguas marítimas que circundan al personaje, objeto de las dos tragedias, es misión de este análisis. En él se reflejará la vinculación de un metafórico mar embravecido a las desdichas de la vida, a la enfermedad y a la muerte; también se hablará de un mar griego vinculado al esplendor, la prosperidad, la belleza y la vida eterna. Cuando el luchador Edipo, el hombre que quiso saber, va alcanzando su fin, cesan en la escena de las palabras determinado tipo de alusiones al mar y va emergiendo, como territorio sagrado de descanso, una ciudad bendecida por 
los dioses y cercana a un mar que se alza con toda su pureza y soberano poder, Atenas. Aquí, en un lugar concreto, cercano a Colono, terminará su vida Edipo, no lejos sin embargo de las aguas dominadas por el dios Posidón (santuario de Posidón), maravillosamente ensalzado en la "Oda a Colono".

\section{EDIPO REY}

Desde los primeros versos de esta tragedia se advierte que el mar ocupará un lugar destacado en la obra; concretamente, en la intervención del sacerdote que ocupa los versos $14-57$, se percibe, como ya dije en otro contexto ${ }^{1}$, su sobrecogedora presencia. Ahora bien, Sófocles no utiliza de forma expresa la palabra thalassa (se constata más tarde el adjetivo thalassion (v. 1411), al final de la obra, cuando ya Edipo se ha perforado los ojos, lo que tiene relevancia, como en su momento se verá) ni pontos, ni okeanos, ni pelagos..., ni cualquier otra posible denominación de las que posee la lengua griega para referirse al mar en su conjunto; lo que nos ofrece Sófocles en esta tragedia es la contemplación de un mar y de sus aguas desde el punto de vista de su tormentosa actividad; por tanto, no resulta extraño que salos y palabras de su familia semántica (saleuei, saleousan...), así como klydona, cheimazo... aparezcan como las preferidas; las otras, tal vez las que esperaríamos, están reservadas para otros contextos, incluida kymata; es más: quiere evitarlas conscientemente porque desvirtuarían su propósito, que no es otro sino presentarnos un retrato impactante de la situación que vive la ciudad de Tebas, aquejada por la peste. Para ello, es preferible, si interpreto bien la intención sofoclea, no servirse de ninguno de los términos que para el pueblo griego eran tan gratos, tan cercanos, tan amados. El mar, las aguas del mar, que en un sutil entramado nos presenta el poeta, carecen realmente del elemento "agua"; han sido privadas de él y han sido sustituidas por la sangre de los tebanos aquejados por la peste; por ello habla de un sangriento "oleaje" o "agitación” o "sacudida" (phoiniou salou, v. 24) y por ello también son traídas al escenario de manera descontextualizada geográficamente; en una palabra, no es el mar griego el que en estos versos se muestra, es la tenebrosa descripción de un mar que en realidad ya no es mar y de un agua que ya está teñida de rojo ("sangrienta"); es una fuerza de la naturaleza que "revuelve", "agita" y "perturba" la tierra (chora) tebana y la ciudad de Tebas. ¿Qué otro escenario más idóneo podría encontrar Sófocles para dibujar la inmensidad del dolor de un pueblo aquejado por la peste? y ¿qué otro ser humano podría estar mejor caracterizado con inmenso poder que el que asume el riesgo de "pilotar la nave del Estado" en esta enorme ola sangrienta que azota como un vendaval la ciudad de Tebas? En realidad, tan importante es la imagen de la ciudad que nos presenta el autor

\footnotetext{
${ }^{1}$ Me refiero a las palabras presentes en "El mar como escenario poético en Edipo Rey de Sófocles”, (Oliveira, Thiercy, Villaça (eds), 2006: 113-126) donde analizo la red metafórica de la obra articulada sobre el mar y su entorno.
} 
como las alusiones de carácter más puntual que aluden al propio Edipo, porque ambas obedecen a una misma idea: Tebas es una nave a la deriva, o un naúfrago que se ahoga en su propia ola sangrienta ("la peste"), porque la ciudad ha sido "envenenada", "manchada" por su "piloto" que no es distinto de Edipo. Dos son, por tanto, los fundamentos de estas marítimas alusiones metafóricas: la situación de la ciudad y su gobernante. Pero Sófocles no se queda en este nivel primario sino que complica el mensaje, añadiéndole, al menos, otro nivel superpuesto, al entretejer un léxico proveniente del lenguaje médico. Todo el conjunto aparece, pues, teñido de una coloración, podemos decir, pesimista, que engloba al ser humano y a la naturaleza enferma en general. Las aguas cristalinas del mar no son las que adornan estos versos sino las turbulentas que, en realidad, cumplen un papel casi dramático en la tragedia. Como opina Segal ${ }^{2}$, uno de los principales temas de la tragedia sofoclea es la relación entre el hombre y la naturaleza, que encarna y simboliza la forma del orden del mundo. Una de las fuerzas principales de la naturaleza, sobre todo para un pueblo como el griego, es el mar. Pero, tal vez sorprendentemente, "el mar de Edipo Rey" no aparece diseñado para constituir un referente positivo, ni tampoco se muestra casi nunca en su aspecto divino, salvo la alusión del coro en la párodo cuando expresa su deseo de alejar esa "peste aborrecible" (loimos echthistos v. 28) fuera de la tierra tebana, hacia el tálamo ingente de Anfitrita ${ }^{3}$ (v.195), es decir, hacia el mar Atlántico. Junto a este tálamo, otra alternativa mucho más acorde con la obra por su tono nos sitúa cerca del Mar Negro, cuando el coro dice o hacia el turbulento oleaje (klydona) de Tracia ${ }^{4}$, inhóspito puerto (vv. 196-97). Las dos alternativas conforman un marco

\footnotetext{
${ }^{2}$ Vide Segal (2013: 267-68). Traducción al castellano de Albino Santos Mosquera: "Edipo Rey probablemente no concede a la tierra un lugar tan central como Antígona, pero son varias las afinidades entre estas dos obras tebanas producidas en el apogeo de la madurez de Sófocles. En ambas piezas, la tierra es un motivo recurrente con el que se refleja un conflicto entre lo que debería ser una relación correcta con los dioses, por un lado, y la confianza de un gobernante en su propio poder, por el otro. Ambas tragedias diferencian entre el "país" o la "región" como territorio político, que tiende a denotar con el término chora, y la "tierra" (ge o chthon) como escenario de lo que es desconocido y oculto en el ser humano.

${ }^{3}$ Vide Jebb (1966: 27), quien comenta esta expresión. Según recoge Grimal (1994: 30-31), "Anfítrite es la reina del mar la que rodea el mundo". Pertenece al grupo de las hijas de Nereo y Doride, las llamadas Nereidas, y dirige el coro de sus hermanas. Danzando un día con ellas cerca de la isla de Naxos, Posidón la vio y la raptó. Se cuenta también que Posidón la amaba, desde hacía mucho tiempo, pero que por pudor la joven lo rechazó, y se ocultó en las profundidades del Océano, más allá de las columnas de Hércules. Descubierta por los Delfines, fue conducida por estos, en medio de un solemne cortejo, a Posidón, quien la hizo su esposa. Desempeñaba junto al dios del mar el mismo papel que Hera junto a Zeus y que Perséfone cerca del dios de los muertos. Se la solía representar rodeada de un numerosos séquito de divinidades marinas".

4 "It remains possible in the case of Threkion kludona to think in particular of the sea near the coast of Salmydessus (as is done by F. Chapoutier, La Mer de Thrace, R.E.G. 1924, 405-410". Vide Kamerbeek (1967: 66). Por su parte, Jebb (1966: 17) señala que "The epithet
} 
de doble plano y doblemente expresado: al lirismo de la primera se une al dramatismo de la segunda para indicar en el fondo una misma cosa: "fuera" (exo) del "suelo" tebano debe marcharse le epidemia, fuera de los confines del mundo habitado, al mar Atlántico, o al mar tracio donde no encontrará kymata sino klydona, porque se trata de un mar continuamente embravecido y porque también la peste y Edipo a su lado, allá donde vayan, provocarán una gran "agitación" (salos) de "enormes olas" (klydona), y, en realidad, aunque el último caso (Tracia) se trata de un referente real de la geografía griega, se encuentra en los confines remotos; concretamente, el lugar aludido lo identifica Chapoutier con algún punto de la costa de Salmydessus, cerca de Medeia. Pero los dos lugares también representan un marco referencial hipotético donde nunca existirá la calma, la salud, la paz. Por tanto, hemos de olvidarnos aquí de un mar lleno de vida, de transparentes aguas y de azul intenso (aquí es phoinos: "sangriento") donde un calmado Posidón o unas risueñas Nereidas nos acompañen. En principio, el mar que contemplamos en estos primeros versos de la tragedia - y en toda ella - está lleno de pavor y de enfermedad, es la propia enfermedad, que afecta a la polis, arrancada de sus raíces terrenales, de su vinculación a la tierra griega. Por eso también resulta importante la tierra (tanto en el sentido de chora como de chthon o ge), porque se sitúa precisamente en el polo positivo de esta dicotomía tierra/ mar. Y, si no teníamos bastante para comprender la magnitud de la desgracia el que se extendiera esta sobre toda la superficie del océano, resulta también que en esa polarización tierra/mar habría que añadir por ahora nosos ("enfermedad") como segundo término adjunto a mar, diseñando ese ámbito de lo no querido, de la desgracia. La relación entre el vocabulario médico y el trágico ha sido estudiada por numerosos especialistas ${ }^{5} \mathrm{y}$, en concreto, se han detectado coincidencias en la terminología verdaderamente interesantes, como las que se dan en estos versos. Es operativo el análisis preciso de algunos términos utilizados magistralmente por Sófocles en la intervención del sacerdote con su poderosa carga semántica. Si tuviera que destacar alguno o algunos de ellos desde la presente perspectiva, naturalmente, me referiría a saleuei, salos, en primer lugar.

threkion here suggests the savage folk to whom Ares is agchiptolis on the W. coast of the Euxine". Salmydessus está situado cerca de Medeia; la zona es descrita por Koromila (2002: $40,206 \ldots$...) con las siguientes palabras: "From the mouth of the Bosphorus as far as the Turkish border with Bulgaria, the area is exposed to the winds. "This is a stony, deserted shore", says Strabo, "much exposed to the north winds".

${ }^{5}$ En concreto ha sido estudiada por Knox (1998: 140-41): In the priest's speech at the beginning of the play there are a number of expressions which suggest that he is appealing to a physician on behalf of a sick patient. "The city", he tells Oedipus,... is storm-tossed, and cannot raise up [anakouphisai, 23] its head out of the depths of the bloody swell". This is figurative language which suggests a swimmer in a heavy sea, or a ship, but it also weaves into the complex pattern the image of a patient fighting a disease, and this suggestion is strengthened by the word "bloody" (phoiniou), which does not seem appropriate for either swimmer or ship". 
Saleuo es un verbo de movimiento que tiene en la literatura griega una aplicación marítima destacada, y su significado lo recoge bien la expresión "ser azotado por la tempestad" o "ser azotado por las olas"; sin embargo, tiene también otros campos de aplicación y puede describir el estremecimiento de la tierra ocasionado por un terremoto; entonces, una opción es traducirlo por "sacudir", "agitar", "ser sacudido" o "ser agitado". Su empleo, aunque no es muy usual, también puede constatarse en el campo de la "enfermedad", como atestigua algún texto, tal el perteneciente al Corpus Hipocraticum ${ }^{7}$; así en Or. Thess. 9.422.13: saleuein kai kata thalassan kai kata kindynous polemikous kai kata arrostias. Por su parte, salos ${ }^{8}$ (literalmente "sacudida"...), sustantivo de la misma raíz, también está presente en la obra hipocrática, concretamente en Praec. 9.256.10, aunque en una alusión metafórica marítima. Es posible constatar su uso aludiendo a la turbación del alma y llegar a adquirir un significado similar a la angustia (Spt. Syr. 40,5). En segundo lugar, y solo en aras de la mejor comprensión del texto, me referiré a anakouphizo (traducido por "alzar la cabeza", v. 23), término también de "doble referencia”, pero de menor interés para este tema, pues no refleja exactamente la caracterización de las aguas sino, más bien, a quien intenta salvarse de ellas. Anakouphisma, sustantivo de la misma raíz, aparece en el Corpus Hipocraticum (De Vict. II 6.580.8) y alude al "alivio" que experimenta un enfermo en su padecimiento. En Edipo Rey figuran en alguna otra ocasión formas de este verbo y sustantivos de la misma raíz, por ejemplo, en el verso 218 (anakouphisin). La primera vez que aparece es justamente en el contexto que estamos refiriendo: kanakouphisai kara ("alzar la cabeza"). El complemento directo de anakouphisai es kara9 ("cabeza"), lo que significaría que el enfermo, el habitante de esa polis

\section{${ }^{6}$ Vid. Anth.11.83.}

${ }^{7}$ Las referencias a las obras Hipocráticas están tomadas del Index Hippocraticus, KühnFleisher (1986). Los textos están tomados de la edición de Littré (1961-1962) y de la de Jones (1923).

${ }^{8}$ Quisiera en esta nota rectificar, en parte, las palabras que, con respecto a este término, aparecen recogidas en mi artículo "El mar como escenario poético en Edipo Rey de Sófocles". En realidad, se produjo un error a la hora de interpretar las palabras de Kamerbeek sobre este término y su significación en la tragedia. Al contrario de lo que allí expresé, Kamerbeek sí reconocía algunas expresiones de la obra relativas a los puertos como alusivas al matrimonio de Edipo y Yocasta, pero no compartía la opinión de H. Musurillo ("Sunken imagery in Sopholes` Oedipus", A.J. Ph. 78 1957: 36-51) en el sentido de que salos en su acepción de "open road-stead" perteneciera a esta línea.

${ }^{9}$ El uso transitivo del verbo kouphizo, según comenta Ceschi (2009: 180-184), es mucho más común que el uso intransitivo, presente también en el Filoctetes (vv. 730-826) de Sófocles. De hecho, Sófocles es el único autor del siglo $V$ ajeno al ámbito de la medicina que utiliza el verbo en su forma intransitiva; se trata de un tecnicismo exclusivo, en el siglo V, de Sófocles y de los escritos hipocráticos.

Guardasole (2000: 69, n. 109) señala la presencia del compuesto anakouphizo en OT 23 y subraya su valor transitivo. Asimismo lo conecta acertadamente con el hápax anakouphisis (OT 218), que a su vez Long (1968: 31) enlaza con el hipocrático anakouphisma (Vict. 64,20 
que es Tebas no puede ni siquiera levantar (anakouphisai), alzar la cabeza fuera de las profundidades o abismos marítimos (bython); en definitiva, no encuentra "un alivio", "un respiro" de su enfermedad.

Para contextualizar los términos reseñados, cito las palabras del sacerdote ${ }^{10}$ y destaco los términos relevantes aquí. No hay que olvidar, sin embargo, que todo el contexto sugiere una negación de la vida, una prevalencia del dolor y una incidencia final en una dicotomía importante que se refleja en la oposición "vacía"11 (kenes), aplicado a la tierra (ges kenes), junto a eremos ("desierta), referido a purgos ("torre") y a naus ("nave"), frente a la otra alternativa: "con hombres" (xun andrasin) lo que es igual a decir "llena". Es importante tal antítesis porque recoge bien la preocupación por la estabilidad y conservación de la tierra $(g e)$ y de sus gentes frente al temor de "un vaciamiento" (este "vaciamiento" o "evacuación”, como se expresa en la nota 12, también puede aplicarse a síntomas de una enfermedad que en Edipo Rey tiene un referente concreto en la peste - loimos -) de la polis, provocado por las consecuencias de la "fuerte tormenta" ("la peste aborrecible"):

La ciudad como tú mismo ves, es víctima de embates excesivos (saleuei), y aún no puede sacar fuera la cabeza del abismo (kanakouphisai kara bython) y del oleaje (salos) sangriento (phoiniou). Se consume (phthinousa) en los gérmenes fructiferos de la tierra, se consume (phthinousa) en los hatos de los bueyes que pacen en los campos, y en los partos estériles (agonois) de las mujeres. Sobre ella se ha abatido y la azota una deidad portadora de fuego (pyrphoros theos), la peste aborrecible (loimos echthistos) que vacía (kenoutai) la mansión de Cadmo, en tanto que el negro (melas) Hades se enriquece de gemidos y lamentos (vv. 22-30)... Ahora, Edipo, tú que eres a los ojos de todos el mejor, te suplicamos todos los aqui postrados ante ti, que encuentres un modo de protegernos, bien lo sepas por haber oído la voz de un dios, bien porque te lo haya comunicado un hombre. Pues son las gentes de experiencia quienes tienen, según creo, más seguro el resultado de los consejos. jEa!, pues, joh tú el mejor de los hombres!, levanta a la ciudad una vez más. jEa!, ten cuidado, pues ahora esta tierra te llama su salvador por tu celo de antaño, no vayamos a recordar tu mando, porque gracias a él nos levantamos para caer después.

Endereza de nuevo esta ciudad con firmeza inquebrantable, ya que con feliz agüero

=VI, 580 L.).

${ }^{10}$ Los fragmentos citados de esta obra pertenecen a la excelente traducción de Luis Gil (1974).

${ }^{11}$ El adjetivo kenos, "vacío”, pertenece a la misma familia semántica que keno (vid. también v. 29 kenoutai) y kenosis; ambas, en el sentido de "evacuación" se emplean en el vocabulario médico. No obstante, y a pesar de que el contexto lo favorece, no creo que Sófocles esté aludiendo indirectamente también a uno de los síntomas de esta enfermedad en los pacientes y lo quiera sugerir al mismo tiempo. 
la ventura de entonces nos procuraste. Ahora, también, muéstrate igual: porque si has de mandar a esta tierra, como la gobiernas, mejor es gobernarla con hombres que vacía. De nada valen una torre o una nave desiertas cuando no hay hombres en ellas. (vv. 46-57).

Como se aprecia por el fragmento citado, este mar aludido, que sacude la nave de Tebas, en las palabras del sacerdote claramente simboliza la descripción de los enfermos afectados por la peste (loimos), por lo que sirve de vehículo para expresar la magna desgracia que ha caído sobre la ciudad. Tal asociación, unida a la conjunción de la presencia del dios portador del fuego (es decir, Ares, que puede ser una personificación de la propia peste), que golpea como un huracán $\left(\right.$ skepsas $\left.^{12}\right)$, y del territorio del Hades, en otro momento definido como "la escarpada costa del dios del ocaso"13 (v. 177), enmarca desde el comienzo los límites donde se va a mover la caracterización del mar en la tragedia. El propio Creonte corrobora la veracidad de lo dicho al enunciar la solución dictada por el mensaje divino; el mal debe ser combatido de la siguiente forma:

Con el destierro de un hombre, o bien haciendo expiar la sangre derramada con un nuevo derramamiento de sangre, como si esa sangre fuera la tempestad que azota (cheimazo) la ciudad. (vv. 100-01)

Cheimazo $0^{14}$ es el término central aquí y, como en los casos anteriores, también puede utilizarse en ámbitos diferentes, siendo uno de ellos el de la enfermedad, al referirse "al punto más álgido de la misma"; así lo encontramos en Hipócrates, Prog. 2.184.4, entre otros lugares (oi mentoi pleistoi auton archontai men poneisthai tritaioi, cheimasontai de malista pemptaioi...). Con su aplicación al ámbito del mar, pues indica precisamente "tormenta en alta mar", colabora a diseñar esa idea de tempestuoso movimiento, de alteración del kosmos, una alteración evidente en todos los términos señalados.

$\mathrm{El}$ tono que adquieren las aguas del mar en Edipo Rey es, otra vez, recordado por el coro, en las últimas palabras de la tragedia, resumiéndonos brevemente la historia del rey tebano Edipo:

Mirad: ése es Edipo, que resolvió aquellos famosos enigmas y fue un hombre de gran-

12 Skeptos-ou significa "huracán” y secundariamente "golpe desprevenido”. El verbo skepto tiene la misma raíz y se utiliza con el valor de "lanzar con fuerza o "lanzarse con fuerza", "caer sobre", entre otras posibilidades.

${ }^{13}$ Acertada traducción de José María Lucas de Dios (2006).

${ }^{14}$ Cheimazo también tiene un ámbito de aplicación en la medicina, por ejemplo, en Sorano: kata thalassan cheimastheisthai "as example of a psychikon pathos", o, como se constata en el v. 1460 de Filoctetes. 
dísimo poder, cuya fortuna, ¿̇qué ciudadano no miraba con envidia? ¡En qué mar embravecida (eis hoson klydona) de horrendas desgracias ha caído; (vv. 1525-1527)

Junto a klydona ("mar embravecido"), los términos salos, saleuei, cheimazon, thalamon Amphitritas, threkion klydona... componen un cuadro que representa a las aguas del mar en su aspecto más negativo, como exponentes de la enfermedad, como agentes de la alteración de un "orden" que exige la tierra (chthon), pero también de la incursión de lo "extraño", del mundo de los otros, que ha contaminado la tierra tebana y que debe retirarse con toda la angustia que ha procurado, para que surja la vida, y el mar pueda definirse con todo su esplendor como el glauke thalassa. Edipo, momentáneamente, recupera ese thalassa, si bien en forma de adjetivo thalassion (v. 1411), una vez ya ciego, para pedir como una de las alternativas ${ }^{15}$ de castigo, ser arrojado al mar, un mar ahora real, que, en prolepsis, está ya purificado, después de la travesía que en otro tiempo fue irónicamente señalada como "feliz" (euploias tychon, v. 423).

\section{EDIPO EN COLONO}

El mar de esta tragedia aparece incluido en la configuración de un espacio sagrado que abarca toda la naturaleza, por lo que no son estas las mismas turbulentas aguas que sacudían los versos de Edipo Rey. El mar del Edipo en Colono comparte su sentir con la "tierra", no forma un "territorio ajeno", "extraño", es parte de Grecia. Por ello interesa, ante todo, definir ese "territorio sagrado", ese espacio compartido. Antes bien, tampoco ha de olvidarse que un mar metafórico, vinculado a expresiones que magnifican y retratan la desgracia, no desaparece por completo del escenario; pero ese mar es un recuerdo de la vida pasada del anciano Edipo, y prototipo de la desdicha de todos los seres humanos; es decir: no conforma el escenario sustancial y peculiar de esta tragedia sino que constituye un paisaje paralelo.

El anciano héroe llega a su puerto final y, a la señal convenida (xynthema, v.46), aguarda su último destino. Los sufrimientos, además del tiempo y la nobleza, han sido sus maestros en la tolerancia (vv.7-8); ciego, errante, acompañado de Antígona, entra en los dominios de Colono (Atenas). Su hija describe el lugar con un acento que revelará a lo largo de la tragedia toda su verdadera eficacia, es un lugar sagrado: choros d’ode hiros (v. 16), descripción recurrente que reaparecerá en boca de otros personajes, como revela también el extranjero interrogado por Edipo:

\footnotetext{
${ }^{15}$ Kamerbeek: cf. 1340 ektópion and other instances listed by Bruhn, Anhang 8. The same connection which exists between 1340 and 166 (see note) is to be found between this wish and that of the Chorus 194 sqq. One may be reminded of the ancient Roman custom of drowning parricides in the sea and also of Greek pharmakos-rites (L. Deubner, Attische Feste pp. 179 sqq.); it is perhaps not too far-fetched to assume that Oedipus` three alternatives are suggestive of the various ways by which pharmakoi were dealt with. Cfr. P. 256 (Kamerbeek).
} 
Todo ${ }^{16}$ cuanto yo sé lo conocerás también al oírme. Sagrado es todo este lugar (choros men hiros pas od 'est). Lo posee el augusto Posidón; y en él está el dios portador del fuego, el titán Prometeo. El sitio que pisas de esta tierra se llama el "umbral de bronce", "baluarte de Atenas". Los campos próximos se glorian de tener por fundador a este jinete que aqui ves, a Colono, y de él toman todos en común el nombre. (vv. 53-60)

Rescato de los versos arriba citados las palabras "lo posee el augusto Posidón", donde se alude al santuario de este dios, mencionado por Pausanias ${ }^{17}$, quien habla de un lugar (choros) llamado Kolonos hippios donde había un altar (bomos) a Posidón hippio, a Atenea hippia, a los héroes Pirito y Teseo, Edipo y Adrasto. Posidón, en efecto, generalmente conocido como la divinidad de las aguas marinas, aparece aquí con prioridad llamado hippios y es el héroe epónimo del demo de Colono bippio. Pero Sófocles no se conforma con citar a Posidón bajo esta advocación sino que le concede un doble papel: por un lado está el Posidón protector de "los caballos" y por otro un Posidón que constituye una referencia al mar en su más augusta, sagrada, mítica forma. Los dos coexisten y los dos son importantes porque configuran un espacio armónico en el que mar y tierra se abrazan fuertemente, y ¿qué mejor opción para configurar un ámbito sagrado que elegir a un dios al cual le está dedicado el santuario donde Edipo descansará y, en el cual, el mar, concebido también como espacio de comunicación, por donde surcan los remos de las naves como medio de transporte, y los caballos, transporte terrestre, se mueven al unísono? Sófocles aspira a "sacralizar" todo el espacio a donde Edipo se dirige en sus últimos momentos y, al tiempo, "sacraliza" también su propio territorio (Colono, Atenas). No se desmarca aquí tampoco de su estilo: la sublime "restricción" sofoclea se adueña de "los dioses", como si "desde un punto común" se desarrollaran dos acepciones que incluso pueden ser dos opuestos: Posidón, porque Sófocles aquí lo ha querido, aparece como protector de su espacio epónimo, y este espacio abarca tierra y mar.

Se observa, por tanto, un cambio en el vehículo expresivo, y el entorno va siendo definido por los protagonistas de forma tal que configura un espacio casi "mágico"; lo daimónico ${ }^{18}$ se apodera del discurso y las aguas del mar, que en Edipo Rey estaban llenas de nosos, de muerte, y en continua agitación, que provocaban

${ }^{16}$ Los textos citados de esta tragedia pertenecen en su mayoría a la traducción llevada a cabo por Benavente (2001). Algún verso de la "Oda a Colono" es de mi autoría.

${ }^{17}$ Vid. Paus. 1.30.4.

${ }^{18}$ Reinhardt (1971: 251-52) ha descrito con gran acierto las peculiares características de "miracle" y "mystère" de esta obra: "Héroïsation et métamorphose concluiaent fréquemment les tragédies attiques...; ici, toutefois, la métamorphose n` est pas simplement prophetisée, surajoutée...; non, ici et exceptionnellement, le miracle et le ravissement deviennent le sens et le but de toute $1^{`}$ action. Du coup, le jeu scénique devient, une dernière fois dans cette dernière 
en los sufrientes tebanos el deseo de su "retirada" hacia otros confines, ahora, estas aguas del mar (y las de los manantiales también) son símbolo de una vida que se manifiesta como eterna $(a e i)^{19} \mathrm{y}$, como tal, constituye el temenos ${ }^{20}$ donde Edipo para siempre descansará incorporado a los daimones de la tierra. Por eso, en esta tragedia, ya no es operativa la oposición ge, thon, chora frente a mar (klydona, salos...); todo es uno: los contrarios se armonizan en un conjunto para que toda la naturaleza acoja al anciano errante; porque ya Edipo no busca salvarse del abismo de las aguas de la vida sino descansar cerca de su seno. La contraposición entre "su ayer" y "su hoy" es claramente expresada por el propio protagonista:

Mas a mi, oh, diosas, según los vaticinios de Apolo, concededme ya el término y desenlace de la vida, si no parezco tener aún insuficiente, yo, que siempre serví a las más terribles penas de los hombres. ¡Ea, oh dulces hijas de la antigua Tiniebla, ea, tú llamada Atenas por la suprema Palas, ciudad la más honrada de todas, compadeceos de la pobre sombra de Edipo, que en verdad no soy el que era antes! (vv. 101-110).

Y este itinerario final del héroe, un héroe humanizado, concluye cerca de la ciudad de Atenas, en Colono, santuario de Posidón. Precisamente la "Oda a Colono" se hace eco, como testimonio inigualable, de las características excepcionales de este territorio; en concreto, su antístrofa final (vv. 709-719) resume poéticamente una de las alabanzas mayores (ainon kratiston, auchema megiston vv. 707-708) que Sófocles dedica a su tierra madre y que constituye también un destacado punto de referencia respecto a la función que el mar cumple en esta obra de despedida:

\section{Yotra alabanza tengo que decir, \\ La mejor, para nuestra ciudad madre,}

oeuvre, légende cultuel, caution, intuition visibles du mystère qu` elle représente comme récit, et qu` elle cèlébre et perpétue par le chant et la danse”.

${ }^{19}$ Son muchas las ocasiones en las que Sófocles se preocupa por dejar claro que la idea de tiempo en esta tragedia está neutralizada; es verdad que existe un "antes", cuando Edipo gobernaba sobre Tebas, y "un después", cuando Edipo ha expiado su culpa y se marcha hacia su último lugar de destino. A partir de aquí, el tiempo no existe, o, se puede decir también, es eterno. Las marcas lingüísticas de ello se esparcen por la obra pero se acumulan en la "Oda a Colono" (vv. 682, 688...)

${ }^{20}$ Reitero en esta nota la aclaración sobre la palabra temenos que figura en C. López Rodríguez (2010: 159): "la raíz está relacionada con el verbo temno, que significa "cortar", por lo que temenos, según testimonian los poemas homéricos (Il. 2.696; 8.48; Od. 8.363), donde aparece la expresión temenos tamon, alude a "una porción de territorio separada del resto y constituye un dominio especial cuyo beneficiario es un ser excepcional, rey, jefe militar o dios; el latín recoge, en su templum, la misma raíz, confiriéndole un valor sagrado. En la literatura posterior a Homero, el término se cita escasamente (Eurip. Herakl. 1329; Hdt. 4.161) y, cuando aparece, el sentido religioso adquiere preponderancia. Vid. H. van Effenterre (1967: 17). 
don de un gran dios y la más alta gloria de esta tierra:

que es de buenos caballos, de buenos potros,

buena en el mar.

¡Oh! Hijo de Cronos, tú en tal honor

la entronizaste, soberano Posidón,

al crear por primera vez en estos caminos

el freno que doma a los caballos;

y el remo de buen bogar,

ajustado a nuestras manos,

brinca, admirable, por el mar

en pos de las Nereidas de cien pies.

He aquí la figura de Posidón, en su doble cariz, pues Sófocles no sólo nos dibuja al más conocido dios de los mares, sino que, como si trazara un círculo perfecto, el menos conocido Posidón terrenal (bippios) se complementa con el poderoso dios del mar, vinculando, por tanto, y como se ha referido ya, dos espacios, tierra y mar en armoniosa síntesis. El término clave, maravillosamente utilizado, es throskei (v. 718), que quiere decir "brinca", y que se suele aplicar literalmente a un "caballo"; pero si este término lo aplicamos al "remo", y decimos que "brinca por el mar”, estamos construyendo una metáfora, y, desglosándola, queremos afirmar que el remo como un caballo brinca por el mar; no solo eso, sino que dos versos anteriores aluden directamente a los caballos, al decir el coro "el freno que doma a los caballos"; luego todo el conjunto aparece intencionadamente mezclado y la forma verbal throskei marca otra vez el zeugma que describe, por un lado la realidad, y, por otro lo metafóricamente aludido. Así como el remo, por alusión metafórica compartida, "brinca por el mar", con mayor propiedad, el caballo, se sugiere, brinca (throskei) por la tierra y debe ser retenido por el freno (ton akestera chalinon v. 714). Y los dos, remo y freno del caballo, son regalo del dios Posidón. Las expresiones lingüísticas de estos versos poseen gran valor no solo poético sino también dramático, pues, al intercambiar términos con doble capacidad de referencia, diseñan en la tragedia la doble o triple función de un dios, cuya importancia en la obra es incuestionable. Termina esta intervención del coro con la hermosa alusión a las Nereidas que son perseguidas por ese remo que "brinca, admirable, por el mar", diseñando Sófocles un cuadro de marcado lirismo y de relajante simpatía. Les adscribe el epíteto de "cien pies", siguiendo una tradición relativamente tardía en los autores griegos (Platón, Critias 116 e). Preside todo ello la consideración de Atenas como ciudad madre, en un sentido de verdadero ser dador de vida y ellos, los colonenses, como sus hijos, cerrando así una personificación que permeabiliza todo el estásimo y que lo convierte también en un ejemplo de delicado animismo.

En esta tragedia no sólo cumplen su función las aguas del mar, también es el 
agua pura de los manantiales (que riega el territorio de Posidón), que, sin reposo (aupnoi krenai v. 685-86), y, eternamente (aien epiemati v. 688), surca el "pecho de esta tierra" (sternouchou chthonos v. 691), entendida como madre. Estas aguas forman parte del suelo que posee vida eterna y son un elemento de ese círculo perfecto de armonía (mar y tierra) que se escucha casi al leer los versos de una inigualable tragedia. Sin embargo, los miembros del coro, por muy especial que vaya a ser la muerte de Edipo, piensan que, a fin de cuentas, el héroe está al final de sus días y, concibiendo su historia como paradigma universal, describen la vejez en tonos apocalípticos, sirviéndose otra vez de las agitadas aguas el mar. En este sentido, parece que estamos retrocediendo al mar metafórico de la desgracia y de la vida:

En ella está este desdichado,
no sólo yo; como un acantilado
que mira al norte, batido por todas
partes por las olas invernales, se estremece,
asi también a éste de arriba abajo
terribles desgracias en oleadas
le estremecen siempre juntas,
unas desde el ocaso del sol,
otras desde donde se alza,
unas desde el mediodia radiante,
otras desde las Ripas envueltas
en la noche. (vv. 1239-1248)

Merece la pena, creo yo, leer parte de este texto en griego, porque Sófocles, ha logrado reproducir no solo mediante la expresión metafórica del acantilado azotado por las olas sino también, fonéticamente, mediante la aliteración de letras tales como la $k$ (presente en akta, kymatoplex, kloneitai, akras, kymatoageis, kloneousin), la imagen de un cuerpo anciano (pues hay una asociación intertextual entre "olas invernales" y "una persona - Edipo - en una vejez avanzada") revolcado (kloneitai), en una especie de circulo $\left(k_{k} k_{l o{ }^{21}}\right)$ de angustia irrompible, de arriba abajo (kat akras). Y no solo aquí aparecen esas aguas revueltas de la desdicha, también el mensajero, tras la "mágica" muerte de Edipo, alude de nuevo al mar evocando su poder destructivo, en un contexto donde la expresión oute pontia thyella kinetheisa toi tote en chronoi (vv. 1659-60) puede tener un mayor valor de referencia real que figurada; no obstante, y dejando al margen la posible ambigüedad, he de decir que enlaza perfectamente con la historia pasada de Edipo y con su constante asimilación a las turbulencias marítimas:

\footnotetext{
${ }^{21} \mathrm{E} 1$ término kyklos no aparece expreso sino fonéticamente sugerido.
} 
Pues no le acabó el ardiente rayo de un dios ni una ráfaga del mar, al alzarse entonces, sino que fue algún enviado de los dioses o, benévolo, se le abrió el sombrio regazo de la tierra de los muertos. Hombre fue que partió sin gemidos y sin el dolor de las enfermedades, sino de forma maravillosa, si alguno de los mortales jamás lo hizo. (vv. 1659-1664).

Como conclusión al papel poético-dramático que cumplen las aguas marítimas en esta tragedia, diré que hay una línea prioritaria, singular caracterizadora del mar en Edipo en Colono: la de elemento configurador de una Arcadia intemporal, que sin embargo tiene un referente concreto en Colono y la tierra Ática, en el santuario de Posidón, donde tierra y mar suenan al unísono incorporados a un mismo entorno poéticamente diseñado: un témenos donde Edipo yacerá reincorporado a los daímones de la tierra; por tanto, un lugar reservado donde "siempre, constantemente" vivirá como protector y donde el agua, bien del mar, bien de los manantiales, bien en forma de su divinidad protectora Posidón, forman parte de tal paisaje. Hay otra línea que conecta con la azarosa historia de Edipo y que participa de la representación de su vida como zarandeada por el oleaje de la desgracia, metafórica por tanto.

Pero unas aguas más pragmáticas son las del futuro de Antígona, y, ¿podríamos decir de la mujer? Son las olas del mar que, junto a las lejanas tierras, constituirán el sendero de un destino que define poéticamente la muchacha como "una noche oscura", mientras que su padre, Edipo, ha muerto como "más podría desearse sin que el ponto lo acometiera":

Del modo que más podría desearse.

¿Y cómo no? Ni Ares

ni el ponto le acometió,

sino que las invisibles llanuras le acogieron

llevado por una oscura muerte;

iay, desdichada, a nosotros una funesta

noche nos cayó sobre los ojos!

¿Cómo, vagando por lejana tierra

o sobre las olas del mar,

conseguiremos el difícil sustento? (vv. 1678-1687) 


\section{Bibliografía}

Amit, M. (1965), Athens and the sea. A study in Athenian sea-power. Bruxelles.

Andreau, J.-Virlouvet, C. (eds.), (2002), L' information et la mer dans le monde Antique. Rome.

Argoud, G. et al. (eds.), (1992), L'eau et les hommes en Méditerranée et en Mer Noire dans l' Antiquité: de l'époque mycénienne au règne de Justinien. Actes du congrès international d' Athènes. Athènes.

Benavente Barreda, M. (1971), Sófocles. Tragedias. Madrid.

Benavente Barreda, M. (2001), Sófocles. Edipo en Colono. Madrid.

Ceschi, G. (2009), Il vocabolario medico di Sofocle. Venezia.

Gil, L. (1974), Sofocles: Antígona, Edipo Rey, Electra. Madrid.

Grimal, P. (1951), Diccionario de Mitología Griega y Romana, Paris. Traducida al castellano por F. Payarols-P. Pericay (1994, 7ª reimpresión).

Guardasole, A. (2000), Tragedia e medicina nell' Atene del V secolo a. C. Napoli.

Jebb, R. C. (1966), Sophocles: The plays and fragments. Part I: The Oedipus Tyrannos. Amsterdam.

Jebb, R. C. (1965), Sophocles: The plays and fragments. Part II: The Oedipus Coloneus. Amsterdam.

Jones, W. H. S (1923), Hippocrates. London-Cambridge.

Jouanna, J. (1995), "Espaces sacrés, rites and oracles dans 1` Oedipe à Colone de Sophocle", REG 108: 38-58.

Kamerbeek, J. C. (1967), The plays of Sophocles, Commentaires. Part IV: The Oedipus Tyrannus. Leiden.

Kamerbeek,J. C. (1984), The plays of Sophocles, Commentaires. Part VII: The Oedipus Coloneus. Leiden.

Knox, B. M. W. (1957), Oedipus at Thebes. New Haven. (reimp. 1998)

Koromila, M. (2002), The Greeks and the Black sea. Athens.

Kühn, J. H. / Fleisher, U. (1986), Index Hippocraticus. Hamburg.

Littré, E. (1961-62 reimpr.), Oeuvres Completes d'Hippocrates I-X. Amsterdam.

Long, A. A. (1968), Language and Thought in Sophocles. London.

López Rodríguez, C. (2006), “El mar como escenario poético en Edipo Rey de Sófocles", in F. Oliveira, P. Thiercy, R. Villaça (eds.), Mar Greco-Latino. Coimbra, 113-126.

Lucas de Dios, J. M. (2006 8a reimpresión), Sófocles: Áyax, Las Traquinias, Antígona, Edipo Rey. Madrid. 
Luque Moreno, J. (2011), Mare Nostrum. Reflexiones sobre el léxico latino del mar. Granada.

Oliveira, F., Thiercy, P., Vilaça, R. (eds) (2006), Mar Greco-Latino. Coimbra.

Palomar, N. (1998), "Visiones del mar en las tragedias de Sófocles: la inestabilidad de la vida humana", Lexis 16:45-61.

Reinhardt, K. (1971 6a ed.), Sophocle. Paris.

Segal, Ch. (1993), Sophocles. Oedipus Tyrannus: Tragic Heroism and the Limits of Knowledge. New York.

Segal, Ch. (1995), Sophocles. Tragic World. London.

Skoda, F. (1988), Médicine ancienne et métaphore. Le vocabulaire de l'anatomie et de la pathologie en grec ancien. Paris.

Sorba, J. (2010), Le vocabulaire de la mer. Étude comparée en indo-aryen ancien, grec ancien et latin. Tesis doctoral. Paris.

Stanford, W.B. (1936), Greek Metaphor: Studies in Theory and Practice. Oxford.

Winnington-Ingram, R. P. (1980), Sophocles: An Interpretation. Cambridge. 